\title{
Invasive Aspergillosis in Refractory Angioimmunoblastic T-Cell Lymphoma
}

\author{
Refrakter Anjiyoimmünoblastik T-Hücreli Lenfomada Invaziv Aspergilloz
}

(D) Prakash NP ${ }^{1}$, (D) Anoop TM ${ }^{1}$, (D) Rakul Nambiar ${ }^{1}$, (D) Jaisankar Puthusseri ${ }^{1}$, (D) Swapna B ${ }^{2}$

${ }^{1}$ Regional Cancer Centre, Department of Medical Oncology, Thiruvananthapuram, India

${ }^{2}$ Regional Cancer Centre, Department of Microbiology, Thiruvananthapuram, India

To the Editor,

A 40-year-old man with angioimmunoblastic T-cell lymphoma, on palliative chemotherapy with lenalidomide at $20 \mathrm{mg}$, developed pancytopenia and progressive loss of vision and conjunctival swelling over the right eye after the second cycle (Figure 1). Brain magnetic resonance imaging with orbit demonstrated endophthalmitis. A pus sample was inoculated onto routine bacteriological media and Sabouraud's dextrose agar (SDA) for detection of fungal pathogens. On the $4^{\text {th }}$ day, fungal growth was observed on SDA. The surface of the fungal colony was initially white; it turned to a bluegreen color and had a powdery texture. Lactose phenol cotton blue mount showed hyaline septate hyphae with short conidiophores and vesicle-bearing chains of round conidia covering the upper half of the vesicle, suggestive of Aspergillus fumigatus. He was started on parenteral voriconazole, but his condition worsened and he died following severe fungal sepsis.

Orbital invasive aspergillosis is a fatal condition, often misdiagnosed, and the mortality rate remains high even after proper treatment. Patients at risk for invasive aspergillosis include patients with prolonged neutropenia, allogeneic hematopoietic stem cell recipients, solid organ transplant recipients, patients on chronic steroid therapy, and patients with HIV infection or chronic granulomatous disease $[1,2]$. Among patients with hematologic conditions (both benign and malignant), the duration and grade of neutropenia predict the risk of invasive aspergillosis. The incidence of invasive aspergillosis in patients with hematologic malignancies has been reported to be as high as 3.1\%, with Aspergillus fumigatus representing the most commonly isolated species [3]. Compared to amphotericin $B$, voriconazole demonstrates a survival benefit, less systemic toxicity, and better tolerance by patients [4].

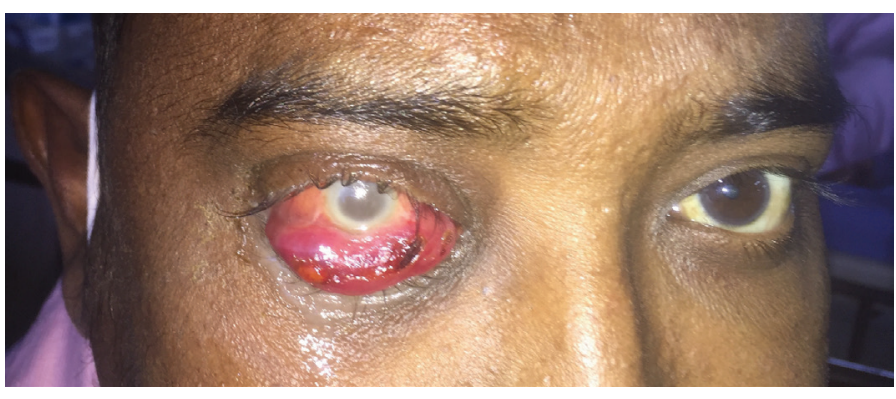

Figure 1. Photograph showing red conjunctival swelling over the right eye.

Keywords: Lymphoma, Endophthalmitis, Aspergillus

Anahtar Sözcükler: Lenfoma, Endoftalmi, Aspergilloz

Conflict of Interest: The authors of this paper have no conflicts of interest, including specific financial interests, relationships, and/or affiliations relevant to the subject matter or materials included.

\section{References}

1. Weinberger M, Elattar I, Marshall D, Steinberg SM, Redner RL, Young NS, Pizzo PA. Patterns of infection in patients with aplastic anemia and the emergence of Aspergillus as a major cause of death. Medicine (Baltimore) 1992;71:24-43.

2. Gerson SL, Talbot GH, Hurwitz S, Strom BL, Lusk EJ, Cassileth PA. Prolonged granulocytopenia: the major risk factor for invasive pulmonary aspergillosis in patients with acute leukemia. Ann Intern Med 1984;100:345-351.

3. Nicolle $M C$, Bénet $T$, Thiebaut $A$, Bienvenu $A L$, Voirin $N$, Duclos $A$, Sobh M, Cannas G, Thomas X, Nicolini FE, De Monbrison F, Piens MA, Picot $S$, Michallet $M$, Vanhems P. Invasive aspergillosis in patients with hematologic malignancies: incidence and description of 127 cases enrolled in a single institution prospective survey from 2004 to 2009. Haematologica 2011;96:1685-1691.

4. Ohlstein DH, Hooten C, Perez J, Clark CL 3rd, Samy H. Orbital aspergillosis: voriconazole - the new standard treatment? Case Rep Ophthalmol 2012;3:46-53. 